Article

\title{
$\beta$-Cyclodextrin as a Functional Excipient Used for Enhancing the Diminazene Aceturate Bioavailability
}

\author{
Narcisa Marangoci ${ }^{1}$, Daniel Timpu ${ }^{1}$, Andreia Corciova ${ }^{2}$, Cornelia Mircea ${ }^{2}$, \\ Anca-Roxana Petrovici ${ }^{1, *}$, Alina Nicolescu ${ }^{1}$, Elena-Laura Ursu ${ }^{1}$, Valentin Nastasa ${ }^{3}{ }^{\circ}$, \\ Andra-Cristina Bostanaru ${ }^{3}(\mathbb{D})$, Mihai Mares ${ }^{3}\left(\mathbb{D}\right.$, Mihaela Pertea $^{2}$ and Mariana Pinteala $1, *(\mathbb{D})$ \\ 1 Centre of Advanced Research in Bionanoconjugates and Biopolymers, "Petru Poni" Institute of \\ Macromolecular Chemistry, 41A Aleea Grigore Ghica Voda, 700487 Iasi, Romania; \\ nmarangoci@icmpp.ro (N.M.); dtimpu@icmpp.ro (D.T.); alina@icmpp.ro (A.N.); \\ ursu.laura@icmpp.ro (E.-L.U.) \\ 2 "Grigore T. Popa", University of Medicine and Pharmacy, 16 Strada Universitatii, 700115 Iasi, Romania; \\ acorciova@yahoo.com (A.C.); corneliamircea@yahoo.com (C.M.); pertea_mihaela@yahoo.com (M.P.) \\ 3 Ion Ionescu de la Brad, University of Agricultural Sciences and Veterinary Medicine, 8 Aleea Sadoveanu, \\ 700489 Iasi, Romania; vnastasa67@gmail.com (V.N.); acbostanaru@gmail.com (A.-C.B.); \\ mycomedica@gmail.com (M.M.) \\ * $\quad$ Correspondence: petrovici.anca@icmpp.ro (A.-R.P.); pinteala@icmpp.ro (M.P.); Tel.: +40-740673523 (A.-R.P.); \\ +40-741025119 (M.P.); Fax: +40-232211299 (A.-R.P. \& M.P.)
}

Received: 16 May 2019; Accepted: 19 June 2019; Published: 22 June 2019

\begin{abstract}
In this study, we proposed formulations of diminazene aceturate (DA) designed to improve its bioavailability and to maximize the therapeutic index in animals by overcoming the rapid degradation under the acidic $\mathrm{pH}$ of the stomach. An important consequence is the fact that its amount in the bloodstream is close to the administered dose. This was made possible by incorporating DA into the $\beta$-cyclodextrin's $(\beta C D)$ cavity in a molar ratio of 1:1. The structure of the resulted inclusion complex was established by Raman, DSC, and Wide-Angle X ray Diffraction (WAXD) in solid state and by ${ }^{1} \mathrm{H}-\mathrm{NMR}$ and H-H ROESY in aqueous solutions. The stoichiometry of the DA: $\beta C D$ inclusion complex was obtained by using the continuous variation method (Job's plot), considering the chemical shifts variations of protons from both DA and $\beta C D$ compounds in ${ }^{1} \mathrm{H}-\mathrm{NMR}$ spectra. The biological activity was estimated in vitro by antioxidant activity and in vivo by comparing the bioavailability of parent DA and its inclusion complexes after a single dose administration in Wistar rats by using the HPLC method on their blood plasma. In vitro tests showed an improved antioxidant activity. In vivo tests have shown that the DA concentration is always much higher in blood plasma of rats when DA: $\beta C D$ inclusion complex of 1:1 molar ratio was administered (i.e., at $60 \mathrm{~min}, \mathrm{DA}$ is around 11 and 3 times higher when $\mathrm{DA}: \beta C D$ inclusion complex of $1: 1$ molar ratio was administered than the parent DA one and DA: $\beta C D$ lyophilized mixture of 1:2 molar ratio, respectively).
\end{abstract}

Keywords: diminazene aceturate; cyclodextrins inclusion complex; antioxidant; bioavailability

\section{Introduction}

In our day, the introduction of more concepts in supramolecular chemistry, which permits the studies of self-assembly of molecules (including polymers), has attracted more and more scientists, becoming a popular area for experimental chemistry, creating a new way for the future not only for the chemists, but for the other researchers (biochemists, engineers, physicists, theoreticians, etc.). Supramolecular chemistry is exploiting physical bonds (like hydrogen bonds, $\pi-\pi$ stackings, or coordination complexation), which are responsible for fabricating new supramolecular materials [1]. 
It should be mentioned that an important factor of supramolecular materials is the reversibility of the formed systems and in this respect, inclusion complexation based on cyclodextrins CDs plays a remarkable role. CDs are cyclic oligosaccharide in which several $\alpha$-D-glucopyranosyl units are connected by 1-3 linkages, forming a truncated cone with a hydrophobic cavity and hydrophilic exterior. $\alpha$-, $\beta$-, and $\gamma$-cyclodextrins $(6,7$, and 8 D-glucose residue respectively), (Figure 1B) are the most used for the encapsulation of hydrophobic molecules into their cavities, forming host-guest inclusion complexes [2-5], enabling their use in pharmacology. By using the CDs in different formulations, the solubility, stability, sensory properties, and biological effects of the guest molecules are improved, and also, from the point of view of the technological process, simple handling, standardized compositions, reduced labor cost etc., can be achieved [6-8].

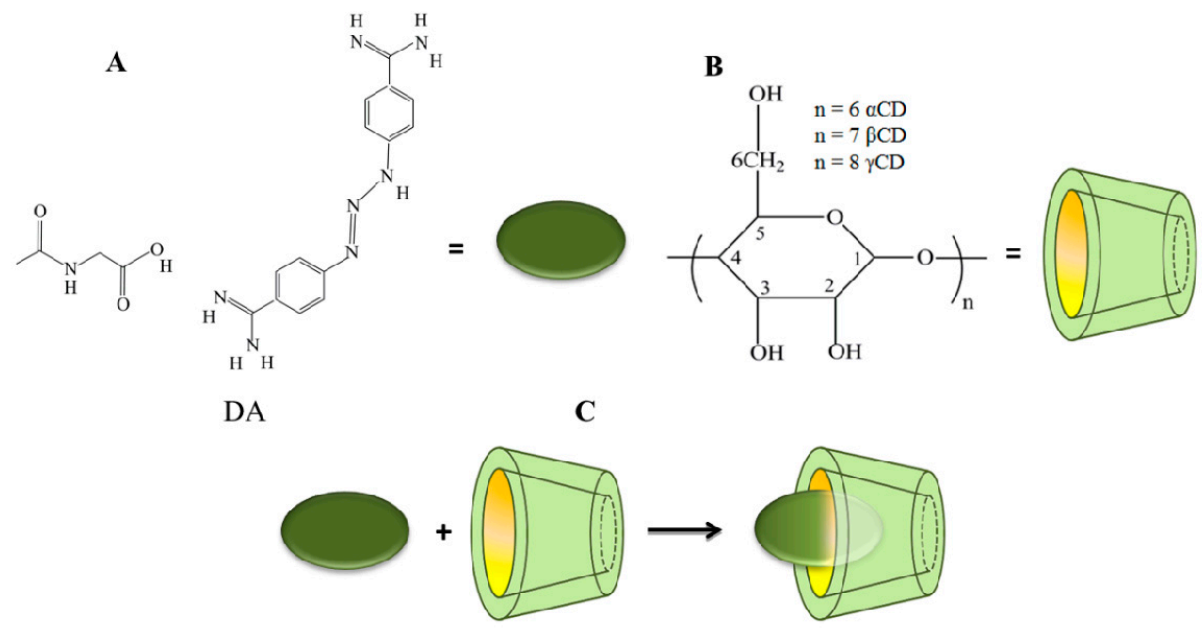

Figure 1. The chemical structures of: (A) DA, (B) $\beta C D$, and (C) schematic representation of the inclusion complex formation.

DA, an aromatic diamidene (4,4'-(1-Triazene-1,3-diyl)bis(benzenecarboximidamide)) (Figure 1A), has attracted attention in recent years due to its therapeutic potential. DA is able to control animal trypanosomiasis and babesiosis [9], being widely used especially in countries of the African continent, Southeast Asia, and South America [10]. Also, new and promising possible pharmacological applications have been found in animal models, such as: asthma [11], gastric mucosal damage [12], ischemic stroke [13], uveitis [14], glaucoma [15], and myocardial infarction [10] by activation of angiotensin-converting enzyme 2 (ACE2). Moreover, it was reported to have the ability to modulate the immune system and thus be able to be used in rheumatoid arthritis by inhibition of the activity of synovial fibroblasts [16]. Other authors showed the involvement in neurodegenerative disorders, such as Huntington's [17] and Alzheimer diseases [18]. Recently, Ge et al. [19] have shown that DA may have anti-inflammatory activity in cases of inflammatory liver disorders.

Most studies show that DA has both antioxidant and antimicrobial activity more or less pronounced according to the administered dose. At the same time, an important problem that must be overcome is to prevent the administration of high doses that may be lethal [20]. As for its chemical stability in aqueous solutions, DA is stable for a few days at neutral $\mathrm{pH}$, while in acidic $\mathrm{pH}$, the molecule is transformed in a few minutes in 4-amino-benzamidine and 4-amino-phenyl-diazonium salt [21]. Besides this, it is strongly recommended to protect DA against direct light due to its photo-instability [22].

As a consequence, further formulations are necessary for DA to ensure a better bioavailability and to maximize the therapeutic index in various animal species, overcoming the rapid degradation in acidic $\mathrm{pH}$ of the stomach and photo-instability, and finally decreasing in its therapeutic doses. Also, it has been mentioned that only simply mixing $\beta C D$ with DA has an increased therapeutic effect on Ichthyophthyrius multifiliis treatment in farmed carp beetles [23]. 
In this context, by complexing DA into the cavity of a cyclodextrin, a positive impact on the physical (solubility and stability enhancement) and biological properties is expected.

Taking all of these aspects into consideration with the work done before in which CDs were used to protect the drugs against degradation in the stomach at low $\mathrm{pH}$ and, consequently, increasing the drug release rate into blood, in this work we propose the complexation of DA into the $\beta C D$ cavity (Figure 1C). The structure of the resulting inclusion complex was established by Raman, Proton ${ }^{1}$ H-NMR, H-H ROESY, X-ray Diffraction Spectroscopy, and DSC methods. The complex stoichiometry was obtained from a Job's plot. The biological activity was estimated in vitro by antioxidant activity and in vivo by comparing the bioavailability of parent DA with its complex with $\beta C D$ after a single dose administration in Wistar rats by using the HPLC method on their blood plasma.

\section{Materials and Methods}

\subsection{Materials}

All reagents and solvents were purchased from Sigma-Aldrich (Merck KGaA, Darmstadt, Germany) and were used as received.

\subsection{Solid Inclusion Complex Preparation}

Synthesis of the DA: $\beta C D$ inclusion complex of 1:1 molar ratio was done by co-precipitation, followed by the freeze-drying method [24]. A 1:1 molar ratio of DA to $\beta C D$ aqueous solution $\left(c_{\beta C D}=50 \mathrm{mg} / \mathrm{mL}\right)$ was stirred continuously at room temperature for $48 \mathrm{~h}$, until the solution became slurry. The obtained mixture was immersed in liquid nitrogen and was submitted for freeze-drying for $24 \mathrm{~h}$ in a Martin Crist, ALFA 1-2LD freeze-dryer. The raw product was washed under vacuum, with small volumes of cold ultrapure water until the guest and host were not present in the filtrate [25]. The solid inclusion complex was noted as DA: $\beta C D(1: 1)$.

The preparation of DA: $\beta C D$ mixture in 1:2 molar ratio was performed in the same manner as the DA: $\beta C D(1: 1)$ complex and was used without purification for in vivo tests. The solid lyophilized mixture was noted as DA: $\beta C D(1: 2)$.

Physical Mixture Preparation of Diminazene Aceturate (DA) with $\beta$-Cyclodextrin ( $\beta C D)$.

Powders DA and $\beta C D$, in a molar ratio of $1: 1$, were mixed in a ceramic mortar prior to analysis.

\subsection{Stoichiometry of the Inclusion Complex and Association Constant Determination}

The stoichiometry of the DA: $\beta C D$ inclusion complex was determined by plotting the chemical shifts variations of the $\mathrm{H}-3$ protons from $\beta C D$ (Figure $1 \mathrm{~B}$ ) and aromatic proton from DA (Figure 1A) as a function of the mole fraction of $\beta C D\left(X_{H}\right)$ and $D A\left(X_{D A}\right)$, respectively.

The association constant (Ka) of the DA: $\beta C D$ inclusion complex was calculated from ${ }^{1} \mathrm{H}-\mathrm{NMR}$ spectra by applying the NMR version of the Benesi-Hildebrand equation $1 / \Delta \delta=1 / \mathrm{Ka} \Delta \delta_{\max }[\mathrm{H}]_{0}+$ $1 / \Delta \delta_{\max }$, where, $\Delta \delta$ is the observed chemical shift difference of the guest for a given cyclodextrin concentration $\left([\mathrm{H}]_{0}\right)$ and $\Delta \delta_{\max }$ is the chemical shift difference between a pure complex and the free guest [26].

\subsection{Physico-Chemical Characterization of $D A: \beta C D$ Inclusion Complexes}

Raman spectra were acquired using dried samples with an InVia Raman Microscope (Renishaw, Gloucestershire, UK), equipped with a He-Ne laser at $632.8 \mathrm{~nm}(17 \mathrm{~mW})$ and a CCD detector coupled to a Leica DM $2500 \mathrm{M}$ microscope. All measurements were performed in backscattering geometry using a 100x objective. The Raman measurements were performed at room temperature and atmospheric pressure. Spectral manipulations were performed with the WiRE 3.2 software (Renishaw, Gloucestershire, UK).

DSC curves were recorded on a DSC 200 F3 Maia device (Netzsch, Selb, Germany). A sample mass of $2.5 \mathrm{mg}$ was heated in aluminum crucibles covered with pierced and pressed lids at a $10^{\circ} \mathrm{C}$ 
$\min ^{-1}$ heating rate in nitrogen atmosphere at a flow rate of $50 \mathrm{~mL} \mathrm{~min}^{-1}$. Device calibration was made with indium.

Wide-Angle $X$ ray Diffraction (WAXD), analyses were performed on a Diffractometer D8 ADVANCE (Bruker AXS, Karlsruhe, Germany), using the $\mathrm{Cu}-\mathrm{K} \alpha$ radiation $(\lambda=0.1541 \mathrm{~nm})$, a parallel beam with Gobel mirror and a Dynamic Scintillation detector. All the samples were investigated for a $2 \theta$ diffraction angle ranging from $2^{\circ}$ to $50^{\circ}$, in stepwise mode to have more accurate diffraction line shapes (count time $2 \mathrm{~s} / \mathrm{step}$, step size $0.02^{\circ}$, at $40 \mathrm{kV}$ and $35 \mathrm{~mA}$ ), at room temperature. The calculus of $2 \theta$ values, interplanar distance $d$, and peak heights were carried out with Bruker "DIFFRAC-PLUS Evaluation-EVA" software. Bruker "TOPAZ" software was used for crystallites size data processing. The calculus was performed according the Bragg's law and Debye-Scherrer formula.

${ }^{1} \mathrm{H}-\mathrm{NMR}$ spectra have been recorded on a Bruker Advance NEO spectrometer operating at $400.1 \mathrm{MHz}$ for ${ }^{1} \mathrm{H}$, using $\mathrm{D}_{2} \mathrm{O}$ as a solvent. For the NMR analysis, a $5 \mathrm{~mm}$ multinuclear direct detection z-gradient probe was used. ${ }^{1} \mathrm{H}-\mathrm{NMR}$ spectra and $\mathrm{H}-\mathrm{H}$ ROESY spectrum were recorded using standard pulse sequences, as delivered by Bruker, with TopSpin 4.0.3 spectrometer control and processing software.

\subsection{DA Calibration Curve}

From a DA stock solution of $5 \mathrm{mg} / \mathrm{mL}$ in Milli-Q water, serial dilutions were made $(0.05 ; 0.1$; $0.3 ; 0.5 ; 0.7 ; 0.9 \mathrm{mg} / \mathrm{mL}$ ) to obtain the calibration curve as DA concentration versus pick area of the registered chromatogram.

\subsection{Stability Studies of $D A$ and $D A: \beta C D$ (1:1) in Acidic and Neutral pH}

Sample preparation: $5 \mathrm{~mL}$ aqueous solutions of DA and DA: $\beta C D(1: 1)$ with concentration of $1 \mathrm{mg} / \mathrm{mL} \mathrm{DA}$ at $\mathrm{pH}=1.2$ (using $\mathrm{HCl}$ ) were prepared (each solution contains $5 \mathrm{mg} \mathrm{DA}$ ). At different time intervals $(0,0.5,1,2,3,4$, and $48 \mathrm{~h}), 10 \mu \mathrm{L}$ of each sample were withdrawn and the HPLC chromatograms were recorded (ESI, Figure S2).

\subsection{Antioxidant Activity of the $D A: \beta C D$ (1:1) Inclusion Complex}

In order to determine the antioxidant activity, the ability of DA and its inclusion compound was used to inhibit the lipoxygenase activity by a modified Malterud method [27], as previously reported by the authors in Reference [3]. The samples' concentrations ranged between 0.0781 and $1.25 \mathrm{mg} / \mathrm{mL}$ for DA and $\beta C D$, and between 0.0234 and $0.375 \mathrm{mg} / \mathrm{mL}$ for the DA: $\beta C D$ inclusion complex. $0.05 \mathrm{~mL}$ of the tested samples were treated with a $0.05 \mathrm{~mL}$ solution containing lipoxygenase in borate buffer ( $\mathrm{pH} 9)$ and after $10 \mathrm{~min}, 2 \mathrm{~mL}$ of linoleic acid solution in borate buffer medium was added. The absorbances of the solutions were recorded at $234 \mathrm{~nm}$, and the ability to inhibit the lipoxygenase activity and the IC50 (expressed in $\mu \mathrm{g} / \mathrm{mL}$ substance in final solution) were calculated.

\subsection{Evaluation of the Drug Release Profile in Blood Plasma from Treated Rats}

\subsubsection{Animals}

A total number of 15 adult female outbred Wistar rats (mean weight $542 \pm 37 \mathrm{~g}$ ) were used (Cantacuzino Institute, Bucharest-Romania). The animals were divided into 3 groups of 5 rats each, hosted in $1500 \mathrm{~cm}^{2}$ polycarbonate cages, and let to acclimatize for $48 \mathrm{~h}$ until the day of the experiment. During this period, all animals had unrestricted access to standard feed and tap water. The following standard microclimate conditions were assured: temperature $22 \pm 0.7^{\circ} \mathrm{C}$, relative humidity $60 \% \pm 10 \%$, and a cycle of 12-h light/12-h dark. Twelve hours before the experiment, the feeding was suspended in order to assure an empty stomach at the moment of gavage. 


\subsubsection{Experimental Design}

DA and the inclusion complexes, $D A: \beta C D$ molar ratio $1: 1$ and $D A: \beta C D$ molar ratio $1: 2$, were tested. All compounds were solubilized in distilled water and a final concentration of $5 \mathrm{mg} / \mathrm{mL}$ DA was assured.

Animals from group A received a single dose of $10 \mathrm{mg} / \mathrm{kg}$ DA orally (by gavage), while those from groups $B$ and $C$ received a similar dose of DA, but as a complex with $\beta C D, D A-\beta C D$ 1:1 and DA- $\beta C D$ 1:2, respectively.

After 30, 60, 120, and $180 \mathrm{~min}$ respectively, $1 \mathrm{~mL}$ blood samples were collected from each animal by cardiac puncture under anesthesia with ketamine $50 \mathrm{mg} / \mathrm{kg}$. The blood was mixed with potassium EDTA to prevent the coagulation, and further processed by centrifugation at $3000 \mathrm{~g}$ in the first $30 \mathrm{~min}$ after the puncture in order to obtain plasma.

After the experiment, all animals were euthanized using injectable pentobarbital sodium (Euthanyl ${ }^{\circledR}$ ).

The study fully complies with the recommendations of Directive 2010/63/EU and was approved by the Ethics Committee of the institution through no 7 from 07.01.2019 Animal test approve.

\subsubsection{HPLC Determination of the Diminazene Aceturate (DA) from Rats' Plasma}

The HPLC determination of DA from rats' plasma was carried out using a Perkin Elmer HPLC system with a Flexar UV/VIS Detector (Waltham, Massachusetts, USA) at $254 \mathrm{~nm}$. A $10 \mu \mathrm{L}$ fixed injection loop was made in a Zorbax SB-C8 (München, Germany), column $(5 \mu \mathrm{m}, 150 \mathrm{~mm} \times 4.6 \mathrm{~mm}$ ) with a $0.5 \mathrm{~mL} / \mathrm{min}$ flow mobile phase consisting in methanol-acetonitrile-Milli-Q water (10:10:80 v/v/v), adjusted to $\mathrm{pH} 4$ with $100 \%$ formic acid [28].

\subsubsection{Blood Samples Preparation}

Prior to the HPLC analysis for quantitative diminazene aceturate determination, the sanguine plasma must be purified by deproteinization. One volume of plasma was vortexed for $20 \mathrm{~s}$ with half volume of $10 \%$ hydrochloric acid. Proteins were separated by centrifugation at $4000 \mathrm{rpm}$ for $10 \mathrm{~min}$ and the $\mathrm{pH}$ of the supernatant was neutralized at 7 with $4 \mathrm{M}$ potassium hydroxide [29].

\subsection{Statistical Analysis}

Data were expressed as the mean value \pm standard deviation (SD) obtained from three measurements. The statistical analysis was performed using the Student's $t$-test and the differences at $p<0.05$ (95\% confidence level) were considered to be significant.

\section{Results and Discussion}

The solid DA: $\beta C D$ inclusion complex of 1:1 molar ratio, obtained by co-precipitation and followed by freeze-drying, was analyzed from the point of view of structure, stoichiometry, and association constant. The biological activity was estimated in vitro (by the determination of the inhibition of lipoxygenase activity) and in vivo (on Wistar rats). For comparison, native DA and DA: $\beta C D$ inclusion complex of 1:2 molar ratio were used.

\subsection{Physico-Chemical Characterization of the DA: $\beta C D$ (1:1) Inclusion Complex}

\subsubsection{Raman Analysis of the DA: $\beta C D$ (1:1) Inclusion Complex}

Figure 2 presents the Raman spectra of dried forms of $D A, \beta C D$, and the DA: $\beta C D(1: 1)$ inclusion complex and DA $+\beta C D$ physical mixture of $1: 1$ molar ratio in the $1700-950 \mathrm{~cm}^{-1}$ wavenumber range. By comparing the Raman spectra of the individual DA and $\beta C D$ components with their 1:1 physical mixture, approximately the sum of the individual molecules was achieved in the Raman spectrum of the physical mixture. From a close introspection on the DA: $\beta C D$ inclusion complex spectrum, 
the main characteristic features of DA and some additional contributions caused by the host-guest interaction can be observed. In this spectrum, a special attention is given to the region above $1550 \mathrm{~cm}^{-1}$ where no interfering bands from $\beta C D$ are present and the changes induced by DA complexation into CD's cavity can be evidenced [30]. DA in this range exhibits a characteristic peak at $1613 \mathrm{~cm}^{-1}$ corresponding to stretching vibrations of the $\mathrm{C}=\mathrm{N}$ group [31] and after its complexation, a slight shift from 1613 to $1611 \mathrm{~cm}^{-1}$, accompanied by its broadening $\left(10.3 \mathrm{~cm}^{-1}\right.$ for $D A ; 13.9 \mathrm{~cm}^{-1}$ for DA: $\left.\beta C D\right)$ can be detected. The broadening of this signal seems to confirm the existence of weak interactions between the cyclodextrin's cavity and the DA atoms involved in the mode assigned to this band [32]. The $1400-1500 \mathrm{~cm}^{-1}$ band of DA are due to $\mathrm{C}-\mathrm{H}$ deformation vibrations, $\mathrm{C}-\mathrm{C}$ stretching vibrations of the phenyl ring, and $\mathrm{N}=\mathrm{N}$ stretching vibrations, but the exact assignment is very difficult since in this region a mixing of vibrations is possible [33,34]. It should also be noted that the bands from 1409,1492 , and $1435 \mathrm{~cm}^{-1}$ of DA are shifted at 1406,1489 , and $1437 \mathrm{~cm}^{-1}$ respectively, in the DA: $\beta C D$ spectrum. Going towards lower wavenumbers, the peaks of DA from $1200 \mathrm{~cm}^{-1}$ and $1172 \mathrm{~cm}^{-1}$, which are attributed to $\mathrm{C}-\mathrm{H}$ scissoring of the phenyl ring and $\mathrm{C}-\mathrm{N}$ stretching vibrations, are shifted to a lower wavenumber in a shoulder with maxima at 1184 and $1170 \mathrm{~cm}^{-1}$ respectively, in the DA: $\beta C D$ (1:1) inclusion complex. Since the positions of the peaks are shifted accompanied with changes in their intensities in the DA: $\beta C D$ spectrum, as compared with the free DA spectrum, it is possible to conclude that an interaction between DA and $\beta C D$ has occurred.

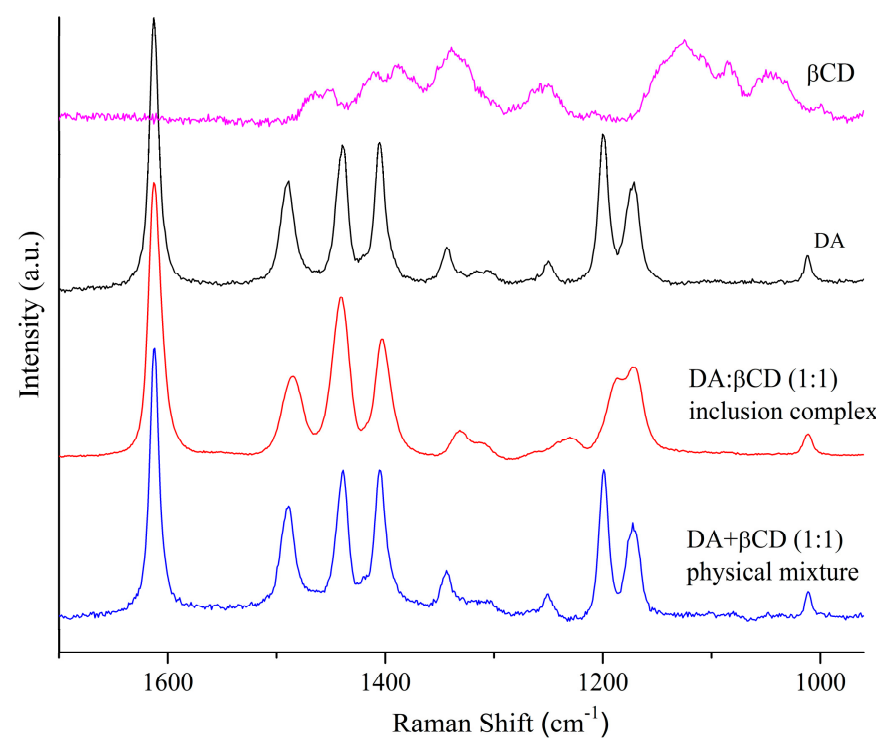

Figure 2. Raman spectra of DA, $\beta C D$, and the DA: $\beta C D(1: 1)$ inclusion complex and $D A+\beta C D$ physical mixture of 1:1 molar ratio in the $1700-950 \mathrm{~cm}^{-1}$ wavenumber range.

\subsubsection{DSC Analysis of the DA: $\beta C D(1: 1)$ Inclusion Complex}

Figure 3 shows the DSC curves of the studied structures. DSC is an analytical method used for identifying host-guest solid-state interactions. Through complexation, the guest molecule is protected by the host molecule. This aspect is usually reflected in reduced and/or displaced melting and decomposition profiles of the guest molecule in the inclusion complex $[35,36]$. The broad endothermic profile (Figure 3 ) centered at $145^{\circ} \mathrm{C}$ corresponds to the loss of crystalized water molecules from the $\beta C D$ cavity. The DA molecule exhibits two endothermic profiles, at $122{ }^{\circ} \mathrm{C}$ and $153{ }^{\circ} \mathrm{C}$, related to salt dehydration. The two endothermic dehydration profiles of the pure drug, together with that of the $\beta C D\left(130^{\circ} \mathrm{C}\right)$, may also be observed in the DSC curve of the physical mixture. The drug thermally decomposes in two phases, described by the exothermic peaks at $160^{\circ} \mathrm{C}$ and $220^{\circ} \mathrm{C}$, which also appear in the DSC curve of the DA in its free state [36]. By analyzing the DSC curve of the DA: $\beta C D$ inclusion complex, it may be observed that the two thermal decomposition profiles of the drug coalesce into a 
significantly reduced one, displaced at $200^{\circ} \mathrm{C}$. This is an indication of the loss of the drug's crystallinity with a new solid phase formation through the complexation of DA inside the $\beta C D$ cavity $[2,37,38]$.

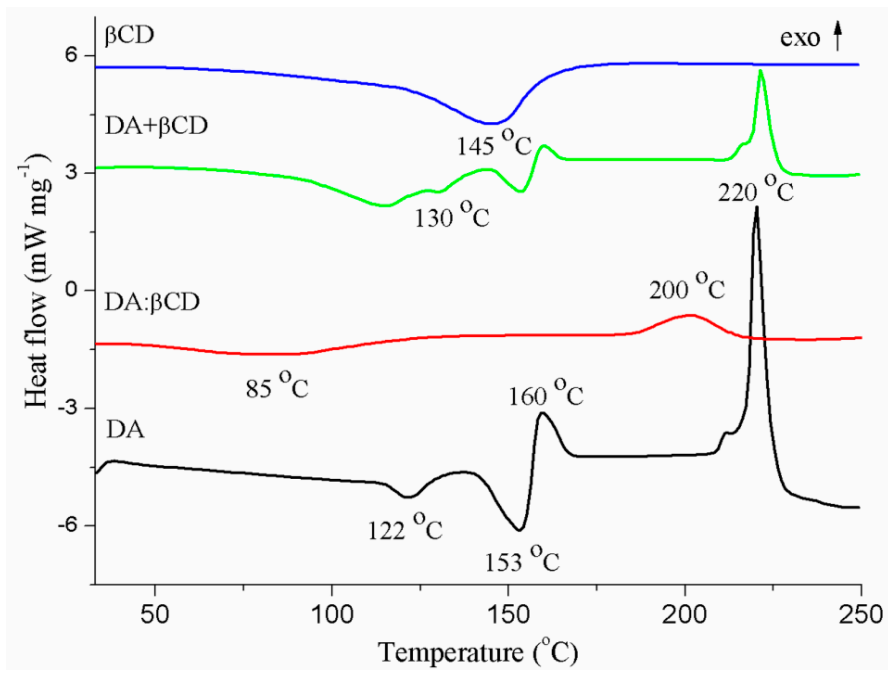

Figure 3. DSC curves of the DA, $\beta C D$, and the DA: $\beta C D$ inclusion complex and DA $+\beta C D(1: 1$ molar ratio) physical mixture.

\subsubsection{Wide-Angle $X$ ray Diffraction (WAXD) Analysis of the DA: $\beta C D(1: 1)$ Inclusion Complex}

The $\beta C D$ and DA precursors are crystalline powders with sharp peaks, which are not influenced by the freeze-drying process or by wetting treatment (ESI, Figures S2 and S3). In both cases, thin shifts of the peak positions can be observed, maybe due to the internal tensions induced by the freeze-drying process. It should be noted that no changes in the initial peaks of $\beta C D$ (ESI, Figure S4) and DA (ESI, Figure S5) were observed after their storage for $18 \mathrm{~h}$ in a saturated water vapor atmosphere.

After the obtaining of the DA: $\beta C D$ (1:1) inclusion complex, both DA and $\beta C D$ precursors lost their crystallinity, (Figure 4, lower diffractogram) and the complex became amorphous as a result of the freeze-drying process; only some small signals remain, perhaps due to the contamination of the complex with traces left of pure $\beta C D$.

In order to better understand the structure of the complex, we kept the DA, $\beta C D$, and DA: $\beta C D$ (1:1) inclusion complex in a saturated atmosphere with water vapors for $18 \mathrm{~h}$. After this, the crystallinity of the complex was restored (Figure 4, red upper diffractogram and inserted image). The peaks of the complex with restored crystallinity (Insert Figure 4, red-lower diffractogram) have the same 2-theta positions, like the initial $\beta C D$ peaks (Insert Figure 4, black-middle diffractogram). No peaks for the initial DA appeared (Insert Figure 4, blue-upper diffractogram), this situation may be explained by the fact that the inclusion of DA into the $\beta C D$ 's cavity is a "molecule to molecule" process, so the crystalline structure (long-distance order) for DA molecules is impossible to appear.

The DA: $\beta C D$ (1:1) complex was also kept for $36 \mathrm{~h}$ in the saturated atmosphere with water vapors, no changes appeared in the registered diffractograms (ESI, Figure S4). 


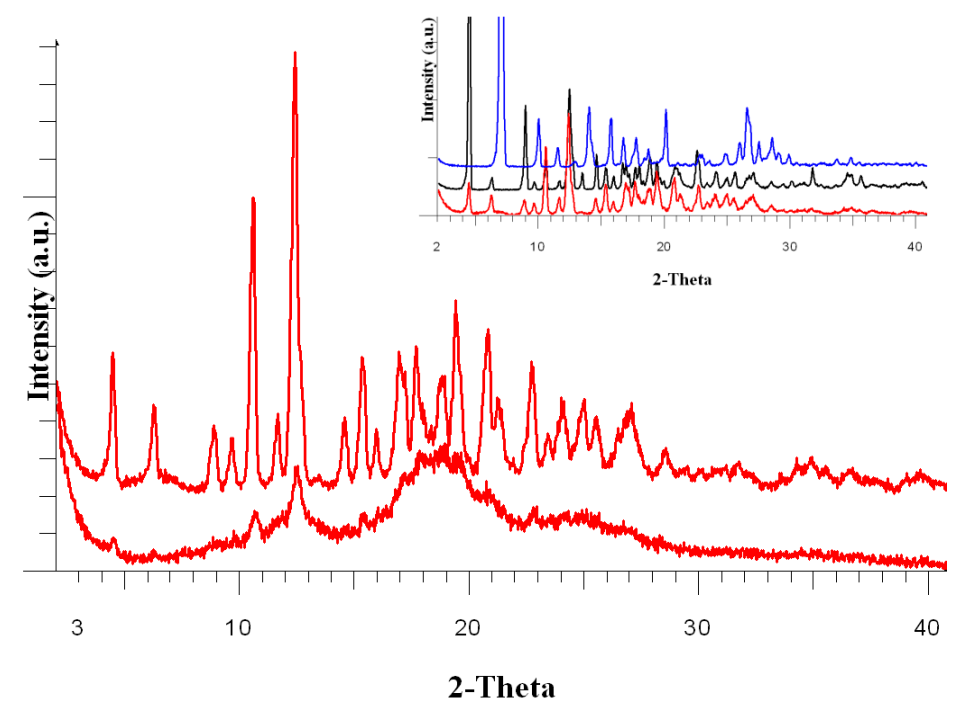

Figure 4. Wide-Angle $X$ ray Diffraction (WAXD) diffractograms of the DA: $\beta C D(1: 1)$ inclusion complex: after the freeze-drying process (red lower diffractogram) and after $18 \mathrm{~h}$ maintained in a water saturated atmosphere (red upper diffractogram). Insert: WAXD diffractograms of the DA: $\beta C D(1: 1)$ inclusion complex after $18 \mathrm{~h}$ maintained in a water saturated atmosphere (red), $\beta C D$ peaks (black-middle diffractogram) and DA (insert, blue-upper diffractogram).

\subsubsection{NMR Spectroscopy Analysis of DA: $\beta C D$ (1:1) Inclusion Complex}

NMR spectroscopy is a well-established technique for the characterization of host-guest interactions. In order to determine the stoichiometry of the DA: $\beta C D$ complex, $10 \mathrm{mM}$ stock solutions of $\mathrm{DA}$ and $\beta C D$ were prepared in $\mathrm{D}_{2} \mathrm{O}$. Starting from these stock solutions, a series of nine samples were obtained, containing both $\mathrm{DA}$ and $\beta C D$, with mole fractions varied from 0 to 1 . Different volumes from each stock solution were mixed so that the total concentration of the final solutions was kept constant to $10 \mathrm{mM}$. The resulting solutions were transferred into $5 \mathrm{~mm}$ NMR tubes and the corresponding ${ }^{1} \mathrm{H}-\mathrm{NMR}$ spectra were recorded.

We followed the DA inclusion into the hydrophobic $\beta C D$ 's cavity by measuring the variations of some protons' chemical shifts of both guest and host molecules. Figure 5 presents the obtained ${ }^{1} \mathrm{H}-\mathrm{NMR}$ spectra for the DA: $\beta C D$ mixtures, with mole fractions varied from 0 to 1 . Changes of the resonance frequencies were observed for the aromatic protons from DA and $\beta C D$ protons.

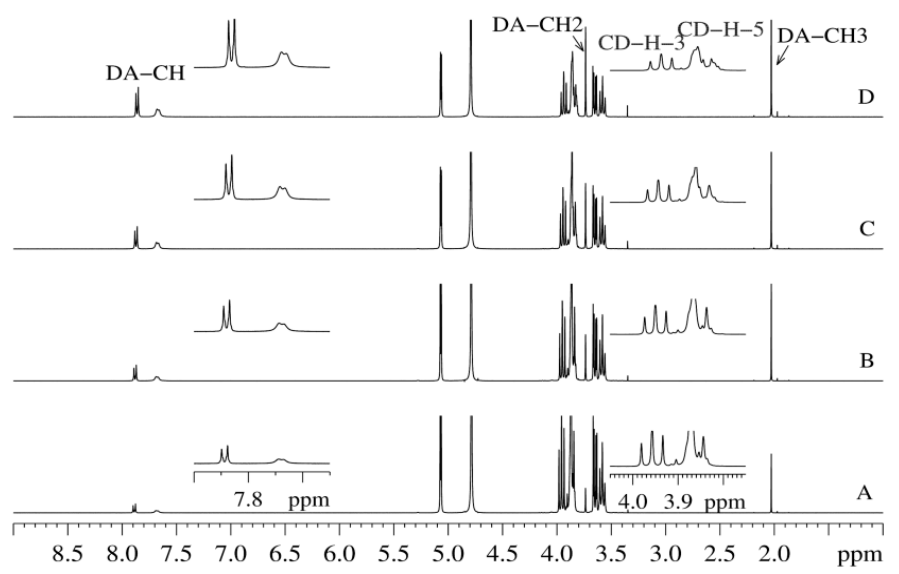

Figure 5. Full ${ }^{1} \mathrm{H}$ NMR spectra of DA: $\beta C D$ mixtures, with mole fractions varied from 0 to $1:$ (A) 0.125 $\mathrm{DA}$ and $0.875 \beta C D$; (B) $0.250 \mathrm{DA}$ and $0.750 \beta C D$; (C) $0.375 \mathrm{DA}$ and $0.625 \beta C D$; (D) $0.500 \mathrm{DA}$ and 0.500 $\beta C D$. The inserts are showing upfield shifts for DA aromatic protons and H-3 and H- $5 \beta C D$ protons, with increasing the DA mole fraction. 
The stoichiometry of the DA: $\beta C D$ inclusion complex was obtained by using the continuous variation method (Job's plot), considering the chemical shifts variations of protons from both DA and $\beta C D$. One of the two DA's aromatic signals has the shape of a broad doublet (Figure 5) and as a consequence, its chemical shift variation is more difficult to follow due to its reading errors. Because of this, we chose to follow the signal from $7.82 \mathrm{ppm}$ only, which has the shape of a well-defined doublet. Regarding the $\beta C D$ protons, we chose to follow the chemical shift variation of the $\mathrm{H}-3$ signal, which is less susceptible to reading errors. The H-5 signal, which is also of interest in complexation NMR studies, is partially overlapped by the $\mathrm{H}-6$ signal, making it more difficult to be observed. The ${ }^{1} \mathrm{H}$ chemical shifts variations of these representative protons as a function of the $\beta C D$ concentration are presented in Figure 6.

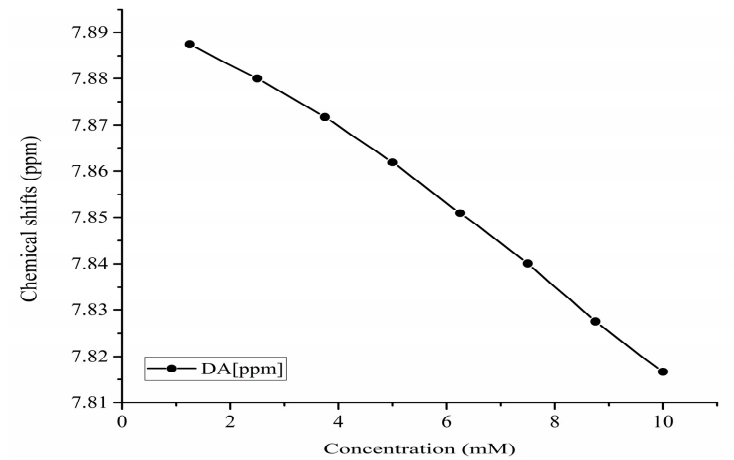

(A)

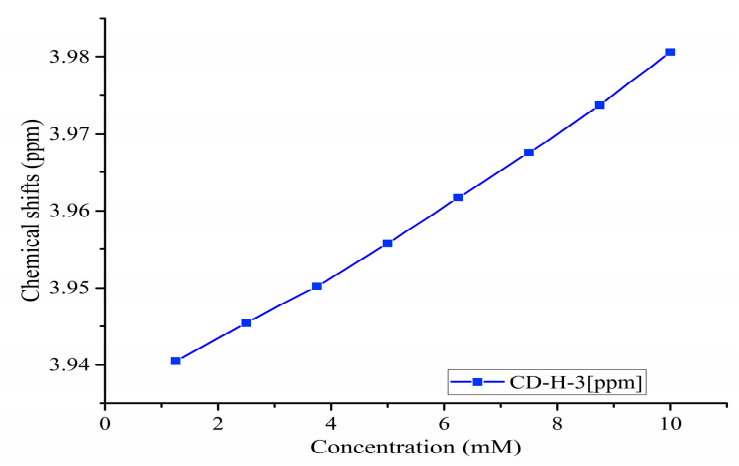

(B)

Figure 6. Chemical shifts variation as a function of $\beta C D$ concentration of: (A) 7.82 ppm protons of DA and (B) $\mathrm{H}-3$ of $\beta \mathrm{CD}$ protons.

It should be mentioned that the chemical shifts of the protons from aceturate residue were not observed in ${ }^{1} \mathrm{H}-\mathrm{NMR}$ studies.

The graphical representations of the induced chemical shifts differences $\left(\Delta \delta^{*} X_{\mathrm{DA} \text { or } \beta C D}\right)$ as a function of mole fraction $X_{\mathrm{DA}}$ or $\beta C D$ are presented in Figure $7 \mathrm{~A}, \mathrm{~B}$. The parameter $\Delta \delta$ is calculated as the difference between the chemical-shifts values in the absence and in the presence of the host or the guest. In both representations, the Job's plot has a maximum at 0.5 , indicating the formation of a complex with 1:1 stoichiometry.

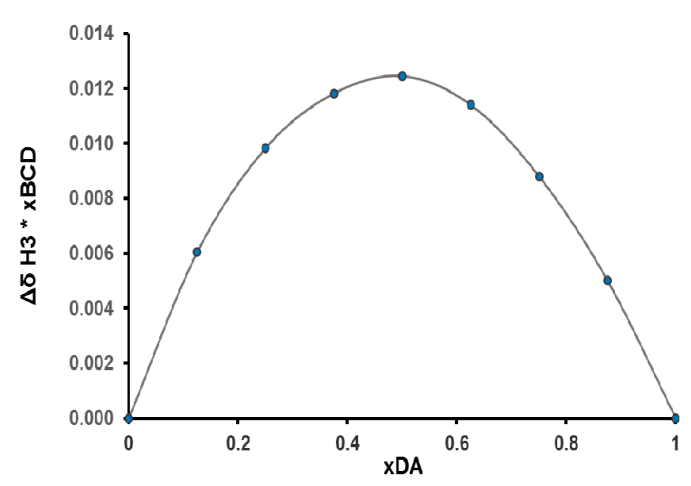

(A)

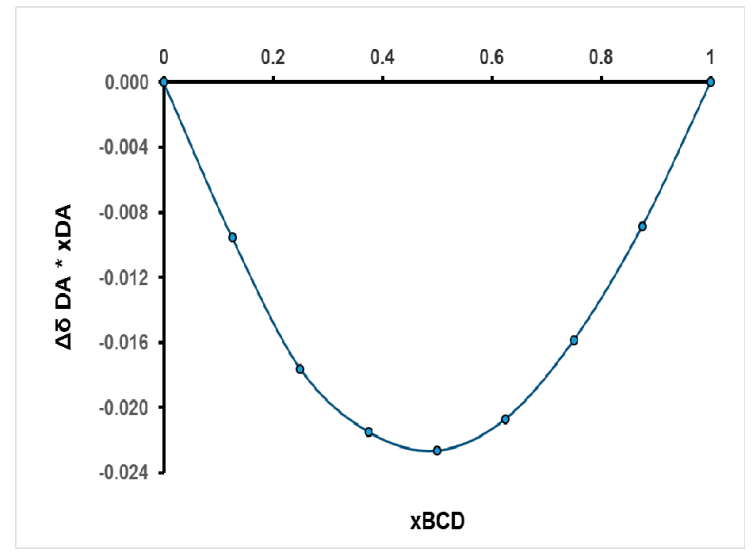

(B)

Figure 7. Job's plots corresponding to chemical shifts variations of: (A) H-3 protons of $\beta C D$ and (B) aromatic proton of DA from $7.82 \mathrm{ppm}$.

Ka of the DA: $\beta C D(1: 1)$ inclusion complex was calculated from the ${ }^{1} \mathrm{H}-\mathrm{NMR}$ data by applying the NMR version of the Benesi-Hildebrand equation (see Section 2.3). In this respect, a new series of 
thirteen solutions were prepared by keeping the concentration of DA constant at $0.1 \mathrm{mM}$ and varying the $\beta C D$ concentration from 0.1 to $16 \mathrm{mM}$. The corresponding ${ }^{1} \mathrm{H}-\mathrm{NMR}$ spectra were recorded and the chemical shifts variations of the DA signal from $7.82 \mathrm{ppm}$ were noted. In Figure 8, the double-reciprocal plot of the NMR version of the Benesi-Hildebrand equation is represented.

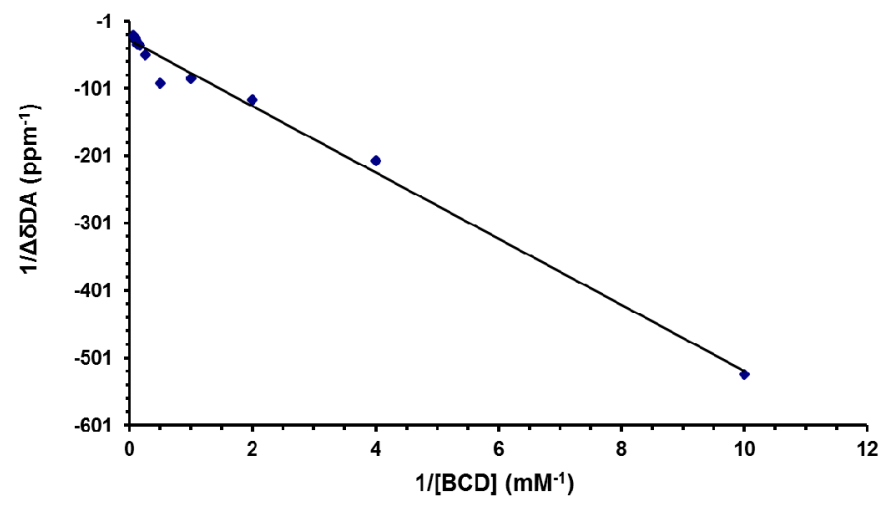

Figure 8. Graphical representation of the Benesi-Hildebrand data treatment.

The straight line confirms the 1:1 stoichiometry of the inclusion complex and from the slope, the value for the Ka was found to be $608.7 \mathrm{M}^{-1}$.

Supplementary information about the DA: $\beta C D$ inclusion complex were obtained from the ROESY experiment when a NOE cross-peak is observed if two protons from different compounds are in spatial vicinity within 3-5 ^. The ROESY spectrum corresponding to the 1:1 DA: $\beta C D$ mixture showed NOE cross-peaks between diminazene aromatic protons and the internal $\beta C D$ protons $\mathrm{H}-3, \mathrm{H}-5$, and H-6 (Figure 9). No NOE cross-peaks were observed between aceturate moiety and $\beta C D$. Also, in the case of the DA: $\beta C D$ lyophilized mixture in a 1:2 molar ratio (named DA: $\beta C D(1: 2)$ ), the existence of a diminazene- $\beta C D$ interaction was demonstrated from the ROESY spectrum, while an aceturate-cyclodextrim interaction has not been confirmed (ESI, Figure S1).

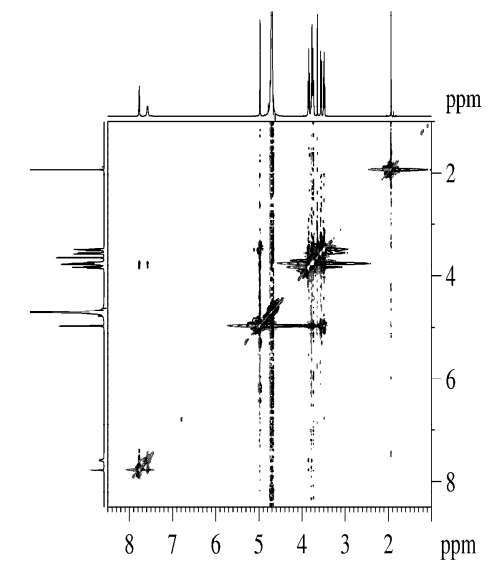

(A)

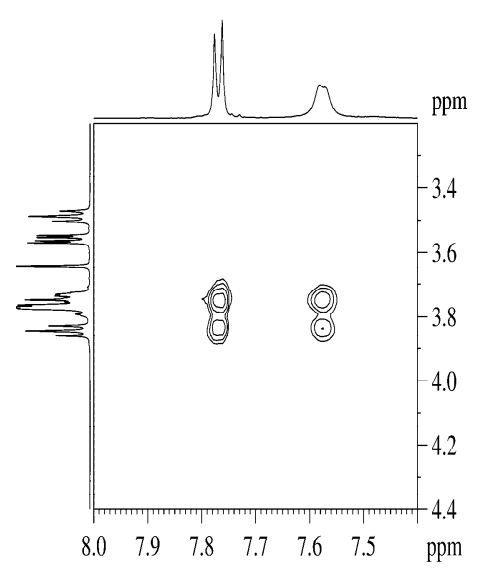

(B)

Figure 9. (A) The ROESY spectrum of DA: $\beta C D$ (1:1) inclusion complex, recorded in $\mathrm{D}_{2} \mathrm{O}$, with suppression of the water signal; (B) Expansion of the ROESY spectrum showing the NOE cross-peaks between phenyl protons of DA and internal $\beta C D$ protons $(\mathrm{H}-3, \mathrm{H}-5)$.

\subsection{Chemical Stability of $D A$ in Acidic and Neutral $p H$ from $D A$ and $D A: \beta C D$ (1:1) Aqueous Solutions}

We performed the chemical stability at $\mathrm{pH}=1.2$ and neutral $\mathrm{pH}$ of DA in free DA and DA: $\beta C D$ (1:1) aqueous solutions. At different time intervals $(0,0.5,1,2,3,4$, and $48 \mathrm{~h}), 10 \mu \mathrm{L}$ of each sample were withdrawn and the HPLC chromatograms were recorded (ESI, Figures S5 and S6). Using the obtained 
pick areas of the DA and of the degraded products together with the DA etalon curve (Figure 10), the remaining percentage of DA and percentage of degraded compounds relative to the DA initial amount at different time intervals were calculated (Figures 11 and 12). As it can be observed in ESI, Figure $\mathrm{S} 2$, at $\mathrm{pH}=1.2$, the degradation of DA occurs suddenly, as soon as it is dissolved in solution. All HPLC spectra show two main peaks, one at around $2.3 \mathrm{~min}$ and the other one around $2.8 \mathrm{~min}$, being attributed to the diminazene and to the degradation products, respectively. According to Figure 11, it should be noted that the free DA dissolved in water at $\mathrm{pH} 1.2$ is totally degraded in the first $48 \mathrm{~h}$, while the DA from the DA: $\beta C D(1: 1)$ acidic solution is still present in $20 \%$ relative to the DA initial amount $(5 \mathrm{mg})$, suggesting that it is a release over time of DA from the cavity of cyclodextrin which acts as a protector to DA. It should also be mentioned that not all existing compounds in the system (e.g., inclusion complex or degraded products) can be detected through the HPLC method $[27,39]$ explaining why not all DA in the system can be detected.

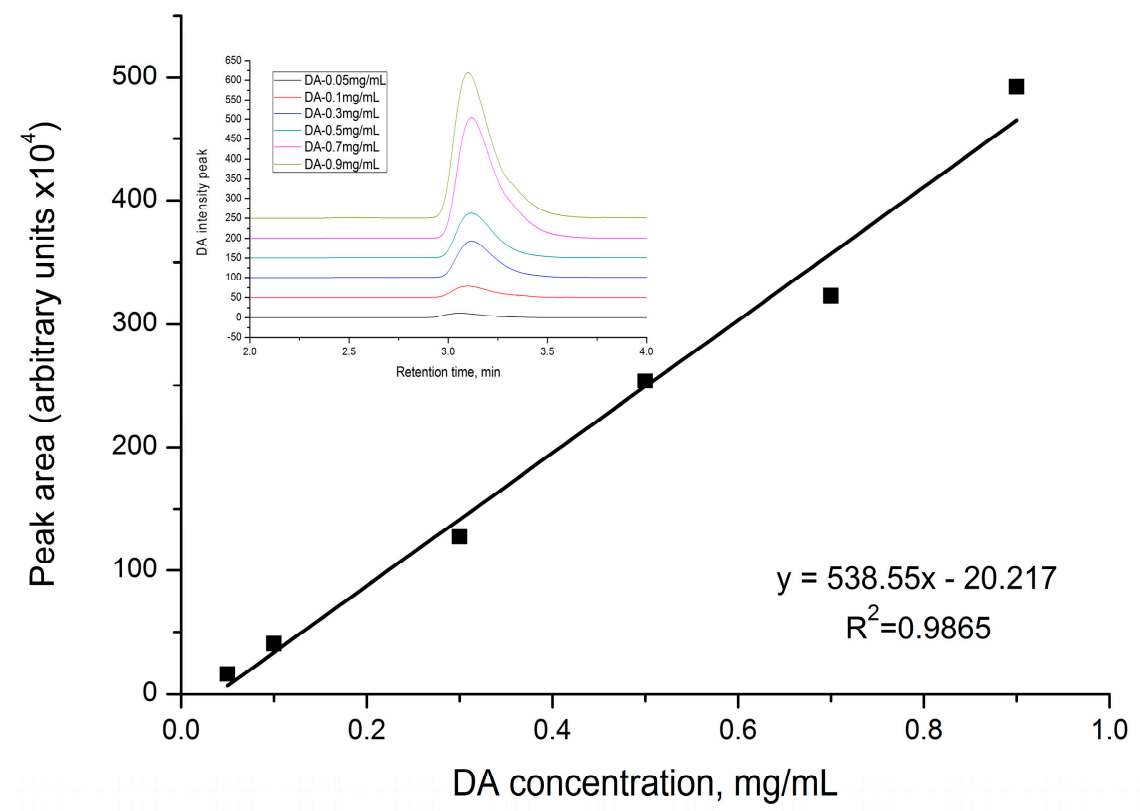

Figure 10. Calibration curve of DA as a function of the DA concentration and peak area of the recorded chromatogram.
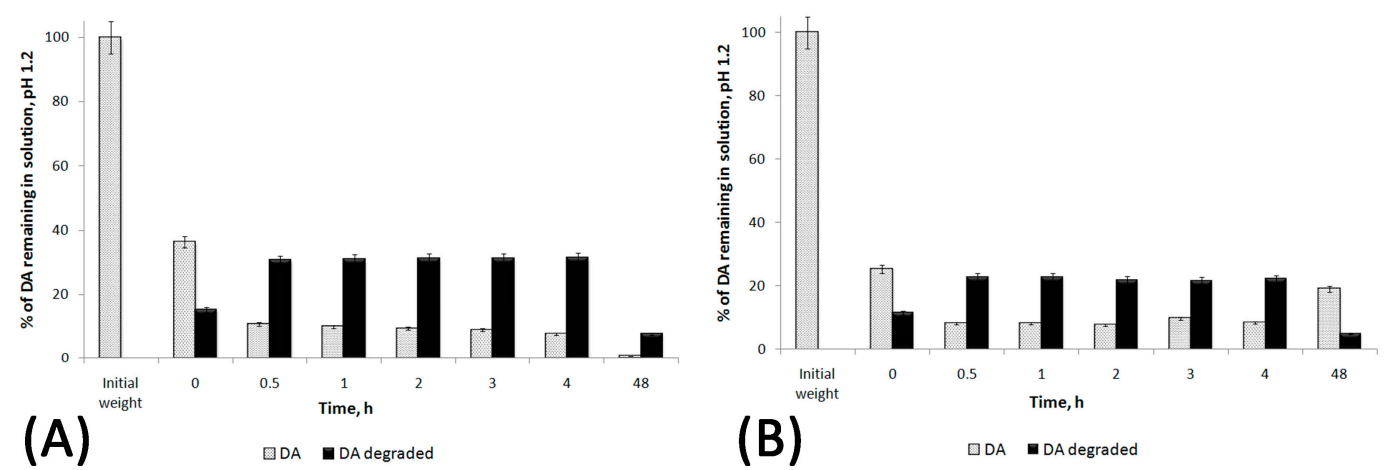

Figure 11. The percentage of DA remaining in water solutions of dissolved DA (A) and the DA: $\beta C D$ (1:1) inclusion complex $(\mathbf{B})$ at $\mathrm{pH} 1.2$ and at different time intervals, using HPLC to analyze.

Using HPLC chromatograms of DA and DA: $\beta C D$ solutions at neutral $\mathrm{pH}$ obtained at different time intervals (ESI, Figure S3) and the calibration curve (Figure 10), the percentages of DA remaining in solutions (reported to the initial amount of DA, $5 \mathrm{mg}$ ) were calculated (Figure 12). Figure 12 reflects that the DA from both types of solutions (dissolving free DA or the DA: $\beta C D(1: 1)$ inclusion complex) 
at the initial time is not degraded as in acidic $\mathrm{pH}$ (Figure 11), but after $30 \mathrm{~min}$. A degradation process occurred in the free DA solution while in the DA: $\beta C D(1: 1)$ solution the DA is stable for at least $4 \mathrm{~h}$, explaining the ability of ciclodextrin to act as the protector of its guest. After $48 \mathrm{~h}$ at room temperature, the DA concentration decreases to less than $50 \%$ in both solutions when HPLC chromatograms of DA degradation revealed the presence of a single compound, which indicates that there are no secondary degradation compounds in PBS (ESI, Figure S3).

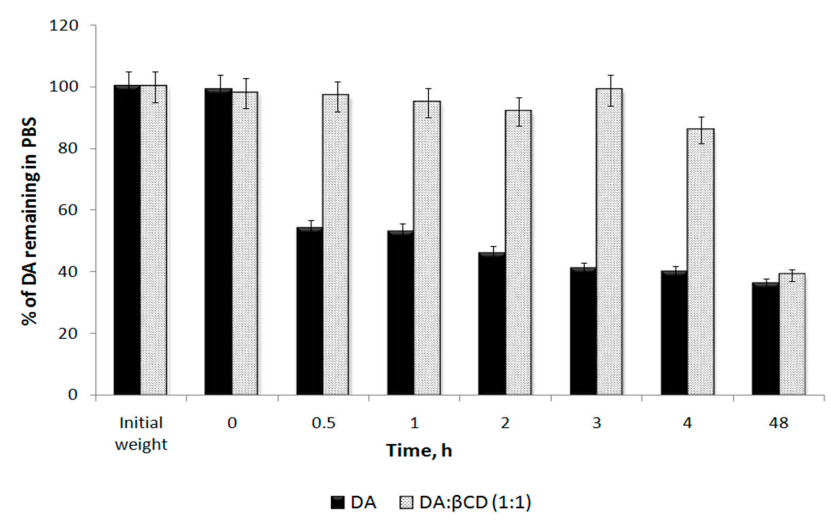

Figure 12. The percentage of DA remaining in PBS solutions of free DA and DA: $\beta C D$ compounds after HPLC analyses.

\subsection{Biological Activity Determination}

The biological activity of the parent DA and synthesized compounds was estimated in vitro by antioxidant activity, and in vivo by measuring the drug's concentration in the rat blood plasma at different time intervals after one dose administration, using the HPLC method.

\subsubsection{Antioxidant Activity of the DA: $\beta C D(1: 1)$ Inclusion Complex}

Antioxidant activity was obtained as previously reported [3]. In fact, the method was based on the ability of tested samples to block lipoxygenase activity by measuring the absorbance of the resulting solutions at $234 \mathrm{~nm}$ (see Section 2.5). As it can be observed from Figure 13, the inhibitory capacity of the samples depends on their concentration but always keeps the following series: DA: $\beta C D>D A>\beta C D$.

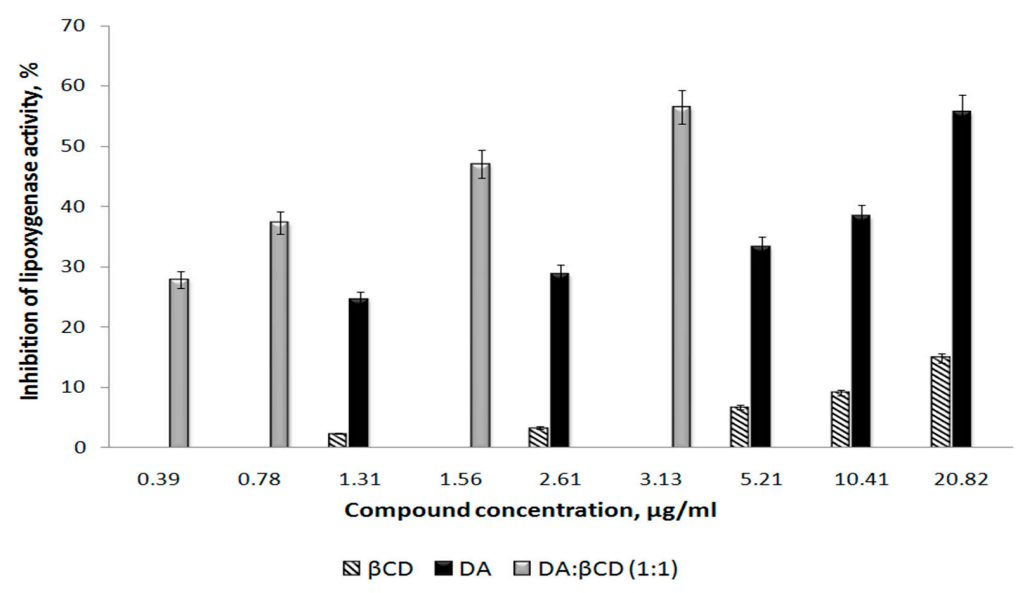

Figure 13. The inhibitory capacity of DA, $\beta C D$, and the DA: $\beta C D(1: 1$ molar ratio) inclusion complex on lipoxygenase activity as a function of DA concentration in the final solution.

Moreover, the DA: $\beta C D$ inclusion complex of 1:1 molar ratio begins to manifest inhibitory capacity against lipoxygenase at a small concentration (approximately $0.4 \mu \mathrm{g} / \mathrm{mL}$ concentration in the final solution) which increases with the increasing DA concentration, administered as its inclusion complex, 
reaching $56 \%$ in its inhibitory capacity at $3.13 \mathrm{DA} \mu \mathrm{g} / \mathrm{mL}$. Meanwhile, parent DA manifests inhibitory capacity at a lower concentration $(1.31 \mu \mathrm{g} / \mathrm{mL})$ but reaches the $55 \%$ inhibitory activity at a much higher concentration $(20.82 \mu \mathrm{g} / \mathrm{mL})$, concluding that the DA: $\beta C D$ (1:1) inclusion complex showed better activity compared to the parent DA. This is also confirmed by the IC50 values. Thus, for the parent substance, a concentration of $16.53 \pm 0.24 \mu \mathrm{g} / \mathrm{mL}$, and for the inclusion compound a concentration of $1.93 \pm 0.05 \mu \mathrm{g} / \mathrm{mL}$, are required to achieve a $50 \%$ inhibition ability. The stronger inhibitory effect of the inclusion complex can be explained by its larger size compared to the parent DA, blocking the access of linoleic acid to the enzyme center, leading to inhibiting lipoxygenase activity [40].

\subsubsection{Evaluation of the Drug Release Profile in Blood Plasma from Treated Rats}

The aim of this study was to comparatively assess the bioavailability of DA and its complex with beta-cyclodextrin of 1:1 and 1:2 molar ratios after a single dose administration in Wistar rats (see Section 2.6). The DA: $\beta C D$ in a molar ratio of $1: 2$ was used for comparing native DA with the DA: $\beta C D$ complex of 1:1 molar ratio. The blood samples were collected and prepared for HPLC analyses following the protocol described in Section 2.6 from Materials and Methods. From all obtained chromatograms, the DA-specific picks areas were determined. By using a DA calibration curve (Figure 11), the real concentrations of DA from blood plasma samples were obtained, which led to determining the variation of DA concentration as a function of sampling time and types of the administered compound in Wistar rats (Figure 14). Herein, we can observe that the DA concentration was always much higher in the blood plasma of rats when the DA: $\beta C D$ inclusion complex of 1:1 molar ratio was administered (i.e., at $60 \mathrm{~min}$, DA was 11 times higher when the DA: $\beta C D$ inclusion complex was administered compared to the parent DA one). This confirms our request to increase DA bioavailability, protecting the DA against its degradation in acidic $\mathrm{pH}$ from the stomach and implicitly increasing its amount into the bloodstream, close to the administered dose.

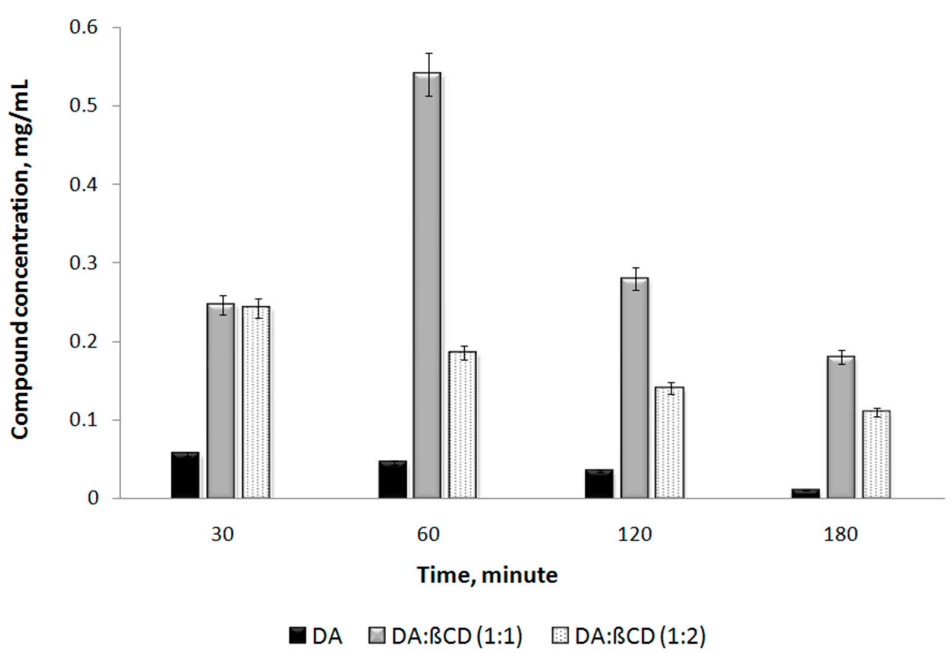

Figure 14. DA concentration in rats' plasma as a function of time and types of administered compound.

\section{Conclusions}

The formation of the 1:1 molar ratio inclusion complex between DA and $\beta C D$ was demonstrated by different techniques (in solid state: Raman, DSC, and WAXD, and in solution: ${ }^{1} \mathrm{H}-\mathrm{RMN}$ and ROESY), its stoichiometry was determined from the Job's plot data, and the association constant of $608.7 \mathrm{M}^{-1}$ was determined from the Benesi-Hildebrand data.

The IC50 value of the DA: $\beta C D$ (1:1) inclusion complex against lipoxygenase was $1.93 \pm 0.05 \mu \mathrm{g} / \mathrm{mL}$ while that of the parent DA was $16.53 \pm 0.24 \mu \mathrm{g} / \mathrm{mL}$. In vivo tests have shown that the bioavailability of DA has been increased due to its protection against degradation in the acidic $\mathrm{pH}$ of the stomach through its encapsulation into $\beta C D$ 's cavity at amounts close to the administered dose. In contrast, 
when the parent DA was administered, the determined bioavailability was very low, meaning that a high amount of DA was degraded by the low $\mathrm{pH}$ of the stomach. Overall, the obtained data suggest that the administration of DA as its inclusion complex with $\beta C D$ considerably reduces the necessary administration dose, making it possible to use this formulation in the treatment of diseases that required up to now high doses of parent DA, thus eliminating the risk of administering lethal doses.

Supplementary Materials: The following are available online at http://www.mdpi.com/1999-4923/11/6/295/s1, Figure S1. (A) The ROESY spectrum of DA: $\beta C D$ inclusion complex of $1: 2$ molar ratio, recorded in $\mathrm{D}_{2} \mathrm{O}$, with suppression of the water signal; (B) Expansion of the ROESY spectrum showing the NOE cross-peaks between diminazene aromatic protons and the internal $\beta C D$ protons $\mathrm{H}-3, \mathrm{H}-5$ and $\mathrm{H}-6$. Figure S2. WAXD diffractograms of DA: $\beta C D(1: 1)$ after $18 \mathrm{~h}$ (red diffractogram) and $36 \mathrm{~h}$ (green diffractogram). Figure S3. WAXD diffractograms of initial $\beta C D$ (black-lower); after the freeze-drying process (brown-middle); after 18 hours in water saturated atmosphere (brown-upper). Figure S4. WAXD diffractograms of initial DA (blue-lower); after the freeze-drying process (brown-middle); after 18 hours in water saturated atmosphere (brown-upper). Figure S5. HPLC chromatograms of: (A) DA and (B) DA: $\beta C D$ (1:1) inclusion complex water solutions of $1 \mathrm{mg} / \mathrm{mL} D A$ at $\mathrm{pH}=1.2$. Mobile phase flow: $0.5 \mathrm{~mL} / \mathrm{min}$. Figure S6. HPLC chromatograms of water solutions at neutral $\mathrm{pH}$ (using PBS) of: (A) DA and (B) DA: $\beta C D(1: 1)$ inclusion complex compounds; mobile phase flow: $1 \mathrm{~mL} / \mathrm{min}$.

Author Contributions: Conceptualization, N.M. and M.P.; methodology, N.M. (synthesis), A.C. (in vitro), M.M. (in vivo), D.T. (WAXD), A.R.P. (HPLC), A.N. (NMR) and E.-L.U. (Raman, XRD, DSC); software, E.-L.U.; validation, A.C. (in vitro), M.M. (in vivo), A.R.P. (HPLC), A.N. (NMR), D.T. (WAXD), and E.-L.U. (Raman, DSC); formal analysis, C.M., M.P., A.-C.B.; investigation, all authors; resources, all authors; data curation, all authors; writing —original draft preparation, each authors; writing—review and editing, M.P.; visualization, M.P.; supervision, M.P., A.C., and M.M.; project administration, M.P.; funding acquisition, M.P.

Funding: This research was funded by a grant of the Ministry of Research and Innovation, CNCS-UEFISCDI, project number PN-III-P4-ID-PCCF-2016-0050, within PNCDI III.

Conflicts of Interest: The authors declare no conflict of interest.

\section{Abbreviations}

$\begin{array}{ll}\text { CDs } & \text { cyclodextrins } \\ \beta C D & \text { beta-cyclodextrin } \\ \text { diminazene aceturate } \\ \text { DA: } \beta C D(1: 1) & \text { inclusion complex in 1:1 molar ratio of components } \\ \text { DA: } \beta C D(1: 2) & \text { lyophilized mixture in 1:2 molar ratio of components } \\ { }^{1} \text { H-NMR } & \text { Proton Nuclear Magnetic Resonance } \\ \text { H-H ROESY } & \text { Rotating Frame Overhause Effect } \\ \text { DSC } & \text { Differential Scanning Calorimetry } \\ \text { HPLC } & \text { High Performance Liquid Chromatography } \\ \text { WAXD } & \text { Wide angle X-ray Diffraction }\end{array}$

\section{References}

1. Garg, R. Supramolecular Chemistry of Host-Guest Inclusion Complexes; GRIN Verlag: Munich, Germany, 2012; Available online: https://www.grin.com/document/187894 (accessed on 16 May 2019).

2. Corciova, A.; Ciobanu, C.; Poiata, A.; Nicolescu, A.; Drobota, M.; Varganici, C.D.; Pinteala, T.; Fifere, A.; Marangoci, N.; Mircea, C. Inclusion complexes of hesperidin with hydroxypropyl- $\beta$-cyclodextrin. Physico-chemical characterization and biological assessment. Dig. J. Nanomater. Bios. 2014, 9, 1623-1637.

3. Corciova, A.; Ciobanu, C.; Poiata, A.; Mircea, C.; Nicolescu, A.; Drobota, M.; Varganici, C.D.; Pinteala, T.; Marangoci, N. Antibacterial and antioxidant properties of hesperidin: Beta-cyclodextrin complexes obtained by different techniques. J. Incl. Phenom. Macrocycl. Chem. 2015, 81, 71-84. [CrossRef]

4. Han, Y.; Liu, W.; Huang, J.; Qiu, S.; Zhong, H.; Liu, D.; Liu, J. Cyclodextrin-based metal-organic frameworks (CD-MOFs) in pharmaceutics and biomedicine. Pharmaceutics 2018, 10, 271. [CrossRef] [PubMed]

5. Marangoci, N.; Mares, M.; Silion, M.; Fifere, A.; Varganici, C.; Nicolescu, A.; Deleanu, C.; Coroaba, A.; Pinteala, M.; Simionescu, B.C. Inclusion complex of a new propiconazole derivative with $\beta$-cyclodextrin: NMR, ESI-MS and preliminary pharmacological studies. Res. Pharm. Sci. 2011, 1, 27-37. [CrossRef] [PubMed] 
6. Chen, G.; Jiang, M. Cyclodextrin-based inclusion complexation bridging supramolecular chemistry and macromolecular self-assembly. Chem. Soc. Rev. 2011, 40, 2254-2266. [CrossRef] [PubMed]

7. Upadhyay, A.J.; Singh, S.; Chhipa, R.R.; Vijayakumar, M.V.; Ajay, A.K.; Bhat, M.K. Methyl- $\beta$-cyclodextrin enhances the susceptibility of human breast cancer cells to carboplatin and 5-fluorouracil: Involvement of Akt, NF-кB and Bcl-2. Toxicol. Appl. Pharmacol. 2006, 216, 177-185. [CrossRef]

8. Zarzycki, P.K.; Fenert, B.; Głód, B.K. Cyclodextrins-based nanocomplexes for encapsulation of bioactive compounds in food, cosmetics, and pharmaceutical products: Principles of supramolecular complexes formation, their influence on the antioxidative properties of target chemicals, and recent advances in selected industrial applications. In Encapsulations, Nanotechnology in the Agri-Food Industry; Grumezescu, A.M., Ed.; Academic Press, Elsevier Science Publishing Co Inc.: Cambridge, MA, USA, 2016; Volume 2, pp. 717-767.

9. Kuriakose, S.; Uzonna, J.E. Diminazene aceturate (Berenil), a new use for an old compound? Int. Immunopharmacol. 2014, 21, 342-345. [CrossRef]

10. da Silva Oliveira, G.L.; de Freitas, R.M. Diminazene aceturate-An antiparasitic drug of antiquity: Advances in pharmacology \& therapeutics. Pharmacol. Res. 2015, 102, 138-157. [CrossRef]

11. Dhawale, V.S.; Amara, V.R.; Karpe, P.A.; Malek, V.; Patel, D.; Tikoo, K. Activation of angiotensin-converting enzyme 2 (ACE2) attenuates allergic airway inflammation in rat asthma model. Toxicol. Appl. Pharmacol. 2016, 306, 17-26. [CrossRef]

12. Souza, L.K.; Nicolau, L.A.; Sousa, N.A.; Araujo, T.S.; Sousa, F.B.; Costa, D.S.; Souza, F.M.; Pacifico, D.M.; Martins, C.S.; Silva, R.O.; et al. Diminazene aceturate, an angiotensin-converting enzyme II activator, prevents gastric mucosal damage in mice: Role of the angiotensin-(1-7)/mas receptor axis. Biochem. Pharmacol. 2016, 112, 50-59. [CrossRef]

13. Bennion, D.M.; Haltigan, E.A.; Irwin, A.J.; Donnangelo, L.L.; Regenhardt, R.W.; Pioquinto, D.J.; Purich, D.L.; Sumners, C. Activation of the neuroprotective angiotensin-converting enzyme 2 in rat ischemic stroke. Hypertension 2015, 66, 141-148. [CrossRef] [PubMed]

14. Qiu, Y.; Shil, P.K.; Zhu, P.; Yang, H.; Verma, A.; Lei, B.; Li, Q. Angiotensin-converting enzyme 2 (ACE2) activator diminazene aceturate ameliorates endotoxin-induced uveitis in mice. Investig. Ophthalmol. Vis. Sci. 2014, 55, 3809-3818. [CrossRef] [PubMed]

15. Foureaux, G.; Nogueira, J.C.; Nogueira, B.S.; Fulgêncio, G.O.; Menezes, G.B.; Fernandes, S.O.A.; Cardoso, V.N.; Fernandes, R.S.; Oliveira, G.P.; Franca, J.R.; et al. Antiglaucomatous effects of the activation of intrinsic angiotensin-converting enzyme 2. Investig. Ophthalmol. Vis. Sci. 2013, 54, 4296-4306. [CrossRef]

16. Neidhart, M.; Karouzakis, E.; Jüngel, A.; Gay, R.E.; Gay, S. Inhibition of spermidine/spermine N1-acetyltransferase activity: A new therapeutic concept in rheumatoid arthritis. Arthritis Rheumatol. 2014, 66, 1723-1733. [CrossRef] [PubMed]

17. Jin, X.; Macdonald, D.; Staunton, J.; Wilson, A.B. Methods and Compositions for the Treatment of Neurodegenerative. Disorders. Patent WO2008021210A2, 21 February 2008. Available online: https://patents.google.com/patent/WO2008021210A2 (accessed on 16 May 2019).

18. Coma, M.; Aloy, P.; Pujol, A.; Gomis, X.; Oliva, B.; Lleó, A.; Mas, J.M. New Combination Therapies for Treating Neurological. Disorders. Patent WO2013061161A2, 2 May 2013. Available online: https: //patents.google.com/patent/WO2013061161A2 (accessed on 16 May 2019).

19. Ge, P.; Yao, X.; Li, J.; Jiang, R.; Dai, J.; Zhang, L. Diminazene aceturate alleviated lipopolysaccharide/D-galactosamine induced fulminant hepatitis in mice. Biomed. Pharmacother. 2018, 98, 142-148. [CrossRef] [PubMed]

20. Miller, D.M.; Swan, G.E.; Lobetti, R.G.; Jacobson, L.S. The pharmacokinetics of diminazene aceturate after intramuscular administration in healthy dogs. J. S. Afr. Vet. Assoc. 2005, 76, 146-150. Available online: https://pdfs.semanticscholar.org/1b36/40339403b50a55bc5131872b2222e0dd8ab3.pdf (accessed on 16 May 2019). [CrossRef]

21. Tiwari, G.; Tiwari, R.; Rai, A.K. Cyclodextrins in delivery systems: Applications. J. Pharm. Bioallied Sci. 2010, 2, 72-79. [CrossRef]

22. Akode, R.M.; Shantier, S.W.; Gadkariem, E.A.; Mohamed, M.A. Simultaneous determination and stability studies on diminazene diaceturate and phenazone using developed derivative spectrophotometric method. Int. J. Anal. Chem. 2017, 2017. [CrossRef] 
23. Lupu, A.-C.; Barbacariu, A.; Roman, C.; Mîndru, R.; Martinescu, G.-V.; Cîmpan, A.-A.; Miron, L.D. In vivo study of conjugated diminazene aceturate for ichthyophthiriosis of farmed carp. Lucrări Științifice Medicină Veterinară 2018, 61, 65-75.

24. Spulber, M.; Pinteala, M.; Harabagiu, V.; Simionescu, B.C. Inclusion complexes of sulconazole with beta-cyclodextrin and hydroxypropyl beta-cyclodextrin: Characterization in aqueous solution and in solid state. J. Incl. Phenom. Macrocycl. Chem. 2008, 61, 41-51. [CrossRef]

25. Lewis, L.N.; Sumpter, C.A.; Sprenne, E.V.; Hedges, A.R.; Romberger, M.L. Purification of Cyclodextrin Complexes. U.S. Patent 5,403,828, 4 April 1995.

26. Fielding, L. Determination of association constants (Ka) from solution NMR data. Tetrahedron 2000, 56, 6151-6170. [CrossRef]

27. Malterud, K.E.; Rydland, K.M. Inhibitors of 15-lipoxygenase from orange peel. J. Agric. Food Chem. 2000, 48, 5576-5580. [CrossRef] [PubMed]

28. Atsriku, C.; Watson, D.G.; Tettey, J.N.A.; Grant, M.H.; Skellern, G.G. Determination of diminazene aceturate in pharmaceutical formulations by HPLC and identification of related substances by LC/MS. J. Pharm. Biomed. Anal. 2002, 30, 979-986. [CrossRef]

29. Koshiishi, I.; Mamura, Y.; Liu, J.; Imanari, T. Evaluation of an acidic deproteinization for the measurement of ascorbate and dehydroascorbate in plasma samples. Clin. Chem. 1998, 44, 863-868. [PubMed]

30. Rossi, B.; Verrocchio, P.; Viliani, G.; Mancini, I.; Guella, G.; Rigo, E.; Scarduelli, G.; Mariotto, G. Vibrational properties of ibuprofen-cyclodextrin inclusion complexes investigated by Raman scattering and numerical simulation. J. Raman Spectrosc. 2009, 40, 453-458. [CrossRef]

31. Socrates, G. Infrared and Raman Characteristic Group Frequencies: Tables and Charts, 3rd ed.; John Wiley \& sons, Ltd.: Chichester, UK, 2001.

32. Iliescu, T.; Baia, M.; Miclăuş, V. A Raman spectroscopic study of the diclofenac sodium- $\beta$-cyclodextrin interaction. Eur. J. Pharm. Sci. 2004, 22, 487-495. [CrossRef] [PubMed]

33. Esme, A.; Sagdinc, S.G. The vibrational studies and theoretical investigation of structure, electronic and non-linear optical properties of Sudan III [1-\{[4-(phenylazo) phenyl]azo\}-2-naphthalenol]. J. Mol. Struct. 2013, 1048, 185-195. [CrossRef]

34. Zimmermann, F.; Lippert, T.; Beyer, C.; Stebani, J.; Nuyken, O.; Wokaun, A. N=N Vibrational frequencies and fragmentation patterns of substituted 1-aryl-3,3-dialkyl-triazenes: Comparison with other high-nitrogen compounds. Appl. Spectrosc. 1993, 47, 986-993. [CrossRef]

35. Mehenni, L.; Lahiani-Skiba, M.; Ladam, G.; Hallouard, F.; Skiba, M. Preparation and Characterization of spherical amorphous solid dispersion with amphotericin B. Pharmaceutics 2018, 10, 235. [CrossRef]

36. Foureaux, G.; Franca, J.R.; Nogueira, J.C.; Fulgêncio Gde, O.; Ribeiro, T.G.; Castilho, R.O.; Yoshida, M.I.; Fuscaldi, L.L.; Fernandes, S.O.A.; Cardoso, V.N.; et al. Ocular inserts for sustained release of the angiotensin-converting enzyme 2 activator, diminazene aceturate, to treat glaucoma in rats. PLoS ONE 2015, 10, e0133149. [CrossRef]

37. Minea, B.; Marangoci, N.; Peptanariu, D.; Rosca, I.; Nastasa, V.; Corciova, A.; Varganici, C.D.; Nicolescu, A.; Fifere, A.; Neamtu, A.; et al. Inclusion complexes of propiconazole nitrate with substituted $\beta$-cyclodextrins: The synthesis and in silico and in vitro assessment of their antifungal properties. New J. Chem. 2016, 40, 1765-1776. [CrossRef]

38. Spulber, M.; Pinteala, M.; Fifere, A.; Harabagiu, V.; Simionescu, B.C. Inclusion complexes of 5-flucytosine with beta-cyclodextrin and hydroxypropyl-beta-cyclodextrin: Characterization in aqueous solution and in solid state. J. Incl. Phenom. Macrocycl. Chem. 2008, 62, 117-125. [CrossRef]

39. Campbell, M.; Prankerd, R.J.; Davie, A.S.; Charman, W.N. Degradation of berenil (diminazene aceturate) in acidic aqueous solution. J. Pharm. Pharmacol. 2004, 56, 1327-1332. [CrossRef] [PubMed]

40. Lu, W.; Zhao, X.; Xu, Z.; Dong, N.; Zou, S.; Shen, X.; Huang, J. Development of a new colorimetric assay for lipoxygenase activity. Anal. Biochem. 2013, 441, 162-168. [CrossRef] [PubMed]

(C) 2019 by the authors. Licensee MDPI, Basel, Switzerland. This article is an open access article distributed under the terms and conditions of the Creative Commons Attribution (CC BY) license (http://creativecommons.org/licenses/by/4.0/). 